\title{
A distinct cyclin-dependent kinase-activating kinase of Arabidopsis thaliana
}

\author{
Masaaki Umeda*†, Rishikesh P. Bhalerao $\ddagger$ Jeff Schell $\$$, Hirofumi Uchimiya*ף, and Csaba Koncz§ \\ *Institute of Molecular and Cellular Biosciences, University of Tokyo, Yayoi 1-1-1, Bunkyo-ku, Tokyo 113-0032, Japan; + Department of Forest Genetics and Plant \\ Physiology, Swedish University of Agricultural Sciences, S-901 83, Umeå, Sweden; §Max-Planck-Institut für Züchtungsforschung, Carl-von-Linné-Weg 10, 50829 \\ Cologne, Germany; and ^Advanced Science Research Center, Japan Atomic Energy Research Institute, Takasaki 370-1292, Japan \\ Contributed by Jeff Schell, February 27, 1998
}

\begin{abstract}
The activation of cyclin-dependent kinases (CDKs) requires phosphorylation of a threonine residue within the T-loop catalyzed by CDK-activating kinases (CAKs). Thus far no functional CAK homologue has been reported in plants. We screened an Arabidopsis cDNA expression library for complementation of a budding yeast CAK mutant. A cDNA, cak1At, was isolated that suppressed the CAK mutation in budding yeast, and it also complemented a fission yeast CAK mutant. cak1At encodes a protein related to animal CAKs. The CAK similarity was restricted to the conserved kinase domains, leading to classification of Cak1At as a distinct CDK in the phylogenetic tree. Immunoprecipitates with the anti-Cak1At antibody phosphorylated human CDK2 at the threonine residue (T160) within the T-loop and activated its activity to phosphorylate histone H1. Whereas CAKs in animals and fission yeast are involved in regulation of the cell cycle and basal transcription by phosphorylating the carboxyl-terminal domain (CTD) of the largest subunit of RNA polymerase II, Cak1At did not phosphorylate the CTD. An Arabidopsis CTD-kinase isolated separately from Cak1At was shown to interact with the yeast protein $\mathrm{p}^{1} 3^{\text {suc1 }}$, but it had no CDK2-kinase activity. Therefore, the CTD of RNA polymerase II is probably phosphorylated by a Cdc2-related kinase distinct from Cak1At. cak1At is a single-copy gene in Arabidopsis and is highly expressed in proliferating cells of suspension cultures.
\end{abstract}

In comparison to animals, a unique feature of plant cell cycle control is that quiescent meristematic and differentiated cells of plants are capable of reentering the cell cycle. The activation of cell division and transitions between different phases of the cell cycle are controlled by a family of cyclin-dependent serine/threonine protein kinases (CDKs; refs. 1-5). Cyclins activate $\mathrm{CDKs}$ by changing the conformation at their catalytic sites (6-8). In Arabidopsis, overexpression of a mitotic cyclin stimulates cytokinesis without leading to neoplasia (9). This suggests that activation of the cell cycle in plants is mediated by post-translational activation of CDKs at multiple levels to control normal development of plant tissues. In addition to cyclins, the activation of CDKs requires phosphorylation of a threonine residue within the T-loop of kinase subdomain VIII $(4,6,8)$ by CDK-activating kinases (CAKs). Purification of CAKs from starfish, Xenopus, and mammals identified a heterotrimeric complex composed of a catalytic kinase subunit $\mathrm{p} 40^{\mathrm{MO} 15} / \mathrm{Cdk} 7(10-12)$, a regulatory cyclin H subunit $(13,14)$, and an assembly factor, MAT1 (15-17). A related CAK complex in Schizosaccharomyces pombe consists of Crk1/ Mop1 catalytic and Mcs2 regulatory subunits $(18,19)$. Recently, a CAK named Cak1/Civ1 has been identified in

The publication costs of this article were defrayed in part by page charge payment. This article must therefore be hereby marked "advertisement" in accordance with 18 U.S.C. $\$ 1734$ solely to indicate this fact.

(C) 1998 by The National Academy of Sciences 0027-8424/98/955021-6\$2.00/0 PNAS is available online at http://www.pnas.org.
Saccharomyces cerevisiae. Although Cak1/Civ1 is most similar to members of the CDK family of protein kinases, it displays less than $25 \%$ sequence identity to its closest homologues (20-22). Unlike vertebrate and fission yeast CAKs, Cak1/Civ1 is known to be active as a monomer.

Vertebrate CAKs were identified as subunits of the transcription factor IIH (TFIIH) and shown to phosphorylate the carboxyl-terminal domain (CTD) of the largest subunit of RNA polymerase II (23-25). Crk1/Mop1 of Sch. pombe displays CTD kinase and CDK-activating kinase (CAK) activities $(18,19)$. This indicates that these CAKs play an additional role in transcription $(26,27)$. In contrast, Cak1/Civ1 of $S$. cerevisiae is unable to phosphorylate the CTD and is probably not a subunit of TFIIH $(20-22,28)$. In budding yeast, the closest structural relatives of $\mathrm{p} 40^{\mathrm{MO} 15} / \mathrm{Cdk} 7$ and cyclin $\mathrm{H}$ are respectively Kin28 and Ccl1 (29-31). The Kin28-Ccl1 complex has been reported to associate with TFIIH and readily phosphorylate the CTD of RNA polymerase II, but it does not seem to display CAK activity (31-33). Therefore, in budding yeast two distinct protein kinases regulate the activation of CDKs and basal transcription.

It is likely that plant CAKs also play an essential role in the regulation of cell division, but thus far no CAK activity has been reported in higher plants. To reveal the function of CAK in cell cycle activation, we started to search for CAK activity in Arabidopsis, and we isolated a cDNA encoding a protein kinase related to the CDK family. Here we show that overexpression of this cDNA rescues the temperature sensitivity of fission and budding yeast CAK mutants. Immunoprecipitates with anti-CAK antibody show CDK2 kinase CAK activity, but not CTD kinase activity, which has been assigned to another CDK-related kinase. These results demonstrate that, analogously to regulation in budding yeast, CDK and CTD kinase activities are separately controlled in Arabidopsis.

\section{MATERIALS AND METHODS}

Complementation of Yeast CAK Mutations. A suspension culture was established from callus tissues obtained from root segments of Arabidopsis thaliana ecotype Col-0 and maintained as described (34). S. cerevisiae GF2351 (MAT $\alpha$, civ1-4, ura3, leu2, trp1, lys2, ade2, ade3; ref. 22) and Sch. pombe JM1224 (mcs6-13, cdc2-3w, cdc25-22, leu1-32, $h^{-}$; refs. 18 and 35$)$ were used as hosts for genetic complementation. To construct a cDNA expression library, RNA was isolated 4days after subculturing an Arabidopsis suspension culture (36), and $\operatorname{poly}(\mathrm{A})^{+}$RNA was purified on oligo(dT)-cellulose type 7 (Pharmacia) for cDNA synthesis by using ligation with EcoRI

Abbreviations: CDK, cyclin-dependent serine/threonine protein kinase; CAK, CDK-activating kinase; CTD, carboxyl-terminal domain; GST, glutathione $S$-transferase.

Data deposition: The sequence reported in this paper has been deposited in the GenBank database (accession no. AB009399).

†To whom reprint requests should be addressed. e-mail: mumeda@ imcbns.iam.u-tokyo.ac.jp. 
adaptors according to instructions of the ZAP-cDNA synthesis kit (Stratagene). After digestion with XhoI, cDNAs were inserted into EcoRI-XhoI sites of the yeast expression vector pYX112 (Ingenius, Wiesbaden, Germany), carrying an ARS/ CEN replicon, the triose-phosphate isomerase promoter, and the selectable marker URA3. The cDNA library was used to transform Escherichia coli MC1061 by electroporation, then $7.4 \times 10^{5}$ independent clones were pooled and amplified in a 1.4-liter culture to prepare plasmid DNA. Subsequently, the library was used to transform GF2351 yeast cells by the lithium acetate method (37), and $\mathrm{Ura}^{+}$transformants were selected on minimal glucose plates at $35^{\circ} \mathrm{C}$. Plasmids complementing the civ1-4 mutation were reisolated from the colonies and retransformed into GF2351 cells to check the reproducibility of restoration of growth at $35^{\circ} \mathrm{C}$. The cDNA inserts were excised with EcoRI and XhoI, subcloned into pBluescript II SK (Stratagene), and sequenced by using an automated sequencer (PE Applied Biosystems) and an ABI Prism Cycle Sequencing Kit (PE Applied Biosystems). Nucleotide and deduced amino acid sequences were compared with homologous sequences in the GenBank, EMBL, and DDBJ databases. The clustering was performed by using the program CLUSTAL V (38).

Expression of $c a k 1 A t, c d c 2 a A t$, and $c d c 2 b A t$ in Yeast. Coding regions of Arabidopsis CDKs $c d c 2 a A t$ and $c d c 2 b A t$ were PCRamplified, sequenced, cloned into the EcoRI site of plasmid pYX112, and introduced into yeast GF2351 to select uracilindependent $\left(\mathrm{Ura}^{+}\right)$transformants on minimal glucose plates at $37^{\circ} \mathrm{C}$. To express cDNAs in Sch. pombe JM1224, the coding regions of $c a k 1 A t, c d c 2 a A t$, and $c d c 2 b A t$ were cloned into the BalI site of pREP3, carrying an ARS1 replicon, an NMT1 promoter, and a selectable LEU2 marker. After electroporation of JM1224 cells (39), Leu ${ }^{+}$transformants were selected on minimal plates in the presence or absence of $2.0 \mu \mathrm{M}$ thiamin at $35.5^{\circ} \mathrm{C}$. Cell shape of JM1224 transformants was monitored by growing the cells overnight in minimal liquid medium supplemented with $2.0 \mu \mathrm{M}$ thiamin, then rinsing them in thiamin-free medium, and growing in medium either containing or lacking thiamin for $8 \mathrm{~h}$ at $27^{\circ} \mathrm{C}$. Cells were then transferred to $35.5^{\circ} \mathrm{C}$ and grown overnight with moderate agitation.

Purification and Immunological Detection of Arabidopsis CAK. Protein samples were extracted from an Arabidopsis suspension culture 4 days after subculturing (40), and from yeast cells as described (41), then fractionated by electrophoresis on SDS $12 \%$ polyacrylamide gels and subjected to immunoblotting using an ECL Western Blotting Detection System (Amersham). Polyclonal antibody was raised against the carboxyl-terminal PTSSGFTIEFP peptide of Arabidopsis Cak1At. When immunoprecipitates with the anti-Cak1At antibody were subjected to immunoblotting, antibodies were fixed to the immunoaffinity support Affi-Gel 10 (Bio-Rad) and used for immunoprecipitation.

The CTD coding region from the largest subunit of Arabidopsis RNA polymerase II cDNA (42) was isolated as a blunt-ended NdeI and SalI DNA fragment and cloned in SmaI-SalI sites of glutathione $S$-transferase (GST) gene fusion vector pGEX4T-2 (Pharmacia). The GST-CTD fusion protein was expressed in E. coli BL21 grown overnight at $27^{\circ} \mathrm{C}$ in the presence of $0.1 \mathrm{mM}$ isopropyl $\beta$-D-thiogalactoside (IPTG), and purified by using glutathione-Sepharose 4B (Pharmacia) according to the manufacturer's protocol. Fusion proteins GSTCDK2 (wild type), GST-CDK2 (carrying the K33R mutation), GST-CDK2 (carrying the T160A mutation), and histidinetagged protein A-cyclin A were expressed and purified as described (11).

Arabidopsis protein samples $(100 \mu \mathrm{g})$ were incubated with 5 $\mu \mathrm{l}$ of preimmune or Cak1At antiserum for $2 \mathrm{~h}$ at $4^{\circ} \mathrm{C}$, and were immunoprecipitated with $30 \mu \mathrm{l}$ of $50 \%$ staphylococcal protein A-agarose (GIBCO/BRL) for $1 \mathrm{~h}$ at $4^{\circ} \mathrm{C}$. The immunoprecipitates were washed three times with bead buffer $(50 \mathrm{mM}$
Tris $\cdot \mathrm{HCl}, \mathrm{pH} 7.5 / 5 \mathrm{mM} \mathrm{NaF} / 250 \mathrm{mM} \mathrm{NaCl} / 0.1 \%$ Nonidet P-40/0.1 mM Na $3 V_{4} / 5 \mathrm{mM}$ EDTA/5 mM EGTA) and once with kinase buffer ( $25 \mathrm{mM}$ Hepes-NaOH, pH 7.5/10 mM magnesium acetate). To isolate proteins interacting with yeast p13 ${ }^{\text {suc1 }}$, Arabidopsis protein samples $(100 \mu \mathrm{g})$ were mixed with $30 \mu \mathrm{l}$ of $50 \%$ (vol/vol) p13 $3^{\text {suc1 }}$-agarose (Seikagaku Kogyo, Tokyo) for $2 \mathrm{~h}$ at $4^{\circ} \mathrm{C}$, then the matrix was washed three times with bead buffer and once with kinase buffer. To separate K1 and K2 fractions, Arabidopsis crude protein extract was loaded onto a DEAE-Sepharose column equilibrated with DEAE buffer (20 mM Tris $\cdot \mathrm{HCl}$, pH 7.8/75 mM NaCl/5 mM MgCl $2 / 5$ $\mathrm{mM}$ EGTA/5 mM $\beta$-glycerophosphate $/ 0.01 \%$ Nonidet P-40/1 mM dithiothreitol/1 mM NaF/0.1 $\mathrm{mM} \mathrm{Na}_{3} \mathrm{VO}_{4}$ supplemented with $0.25 \mathrm{mM}$ phenylmethanesulfonyl fluoride, 0.1 $\mathrm{mM}$ benzamidine, and $1 \mu \mathrm{g} / \mathrm{ml}$ both leupeptin and aprotinin), and the flow-through was collected as the K1 fraction. The column was washed with DEAE buffer, and the $\mathrm{K} 2$ fraction was eluted with DEAE buffer containing $0.6 \mathrm{M} \mathrm{NaCl}$.

CDK2, and CTD kinase assays were essentially as described (11). In brief, $0.1 \mu \mathrm{g} / \mu \mathrm{l}$ GST-CDK2 or GST-CTD was mixed with immunoprecipitates, or proteins bound to $\mathrm{p} 13^{\text {suc1 }}$ agarose, and subjected to phosphorylation reactions. For assaying the CTD kinase in the K1 and K2 fractions, GST-CTD was bound to $10 \mu \mathrm{l}$ of glutathione-Sepharose, incubated with either $\mathrm{K} 1$ or $\mathrm{K} 2$ fraction $(130 \mu \mathrm{g})$ for $2 \mathrm{~h}$ at $4^{\circ} \mathrm{C}$. Then the Sepharose matrix was washed three times with bead buffer and once with kinase buffer, and was subjected to phosphorylation reaction. CAK assays were performed as described (11).

Southern and Northern Hybridizations. Genomic DNA was prepared from Arabidopsis Col-0 plants (43), digested with EcoRI, HindIII, BamHI, or SacI, size fractionated by electrophoresis on $0.7 \%$ agarose gels, and transferred to Hybond- $\mathrm{N}^{+}$ membranes (Amersham) according to the manufacturer's instructions. Total RNA samples $(12 \mu \mathrm{g})$ isolated from diverse tissues were fractionated on formaldehyde $/ 1.2 \%$ agarose gels and transferred to a Hybond- $\mathrm{N}^{+}$membrane as described (44). For Southern and Northern hybridizations, an EcoRI fragment of cak1At cDNA, carrying the coding region except for the last three codons, was used as probe. DNA and RNA hybridizations were conducted as described (45).

\section{RESULTS}

Isolation of Arabidopsis cDNAs Complementing the CAK Mutation of Budding Yeast. Division of $S$. cerevisiae GF2351 cells, carrying a temperature-sensitive mutation of the cak1/ civ1 gene, is arrested within one cell cycle after transfer to $37^{\circ} \mathrm{C}$ (22). We screened for Arabidopsis cDNAs, the overexpression of which rescued the temperature sensitivity of GF2351. A cDNA expression library was constructed in pYX112 vector by using a constitutive promoter of triose-phosphate isomerase gene. Screening of $4.8 \times 10^{5}$ transformants resulted in two clones growing well at $35^{\circ} \mathrm{C}$. Both clones contained identical cDNAs flanked by $5^{\prime}$ and $3^{\prime}$ noncoding regions differing in length. Nucleotide sequencing of these cDNAs revealed an open reading frame of $1440 \mathrm{bp}$ coding for a predicted protein sequence of 480 amino acids that showed homology to members of the CDK protein kinase family with a closest similarity to $\mathrm{p} 40^{\mathrm{MO} 15} / \mathrm{Cdk} 7$ (Fig. $1 A$ ). The homology to CDKs was restricted to the conserved kinase domains, including the ATP-binding site (42\% identical), the active site (53\% identical), and the phosphoregulatory site (53\% identical). The gene was therefore termed cak1At for CAK homologue of Arabidopsis thaliana. It was noteworthy that the Cak1At protein carried an extra stretch of 112 amino acids between the kinase active site and phosphoregulatory site (Fig. 1A). A phylogenetic tree analysis showed that Cak1At was distinct from the $\mathrm{Cdc} 2$ and $\mathrm{p} 40^{\mathrm{MO} 15} / \mathrm{Cdk} 7$ kinase families regardless of the presence of the 112 amino acids stretch, suggesting that Cak1At was a novel type of CDK (Fig. 1B). Surprisingly, 
A
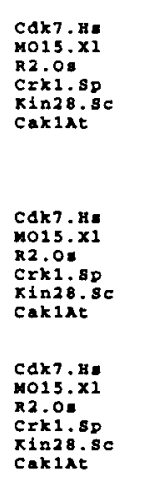

Cdk7.H:
No15:XI
R2.0.

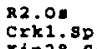

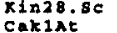

CAk7.He
MO15:XI
R2.0:

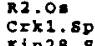

Cakint

R2.0.
ATP-binding site

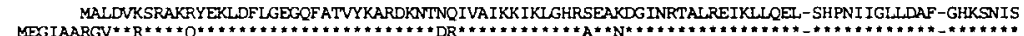

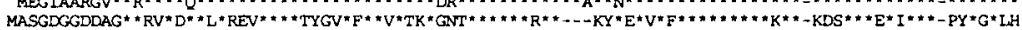

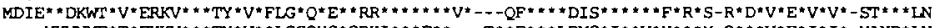

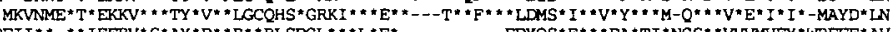

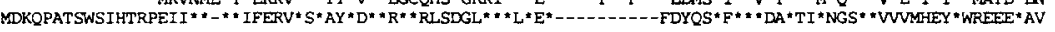

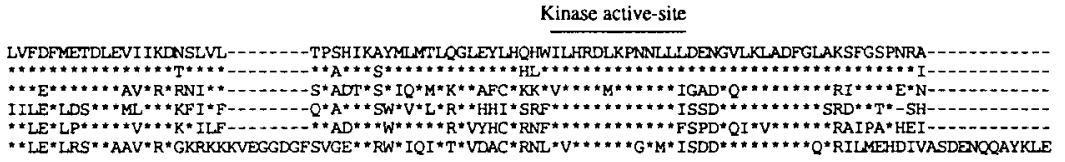

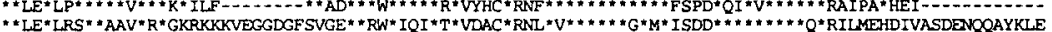

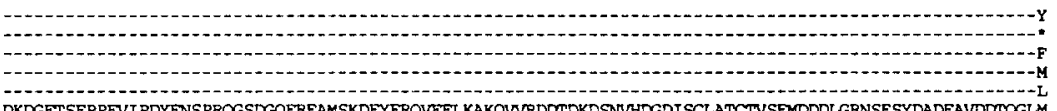

DKDGETSEP PEVI PDYENSPRQGSDGQEREAMSKDEYFRQVEEL KAKQWVDDTDKDSNVHDGDISCLATCTVSEMODDLGRNSFSYDADEAVDDTQGLM

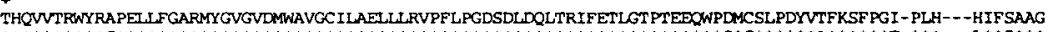

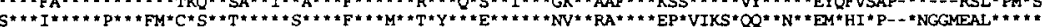

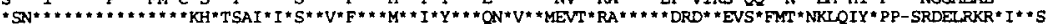

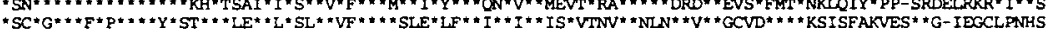
DDLDDLIOGLFLFNPCARITATQALKKMKYFSNRPGPTPGCOLPRPNCPVETLKEQSNPALAIKRKRTEAL.EQGGLLPKKLIF

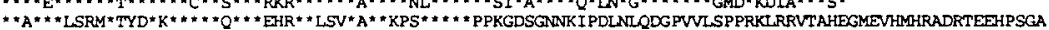

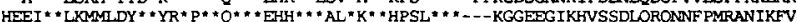

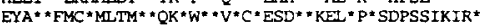

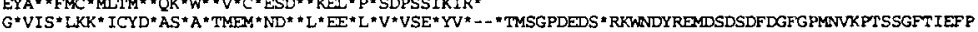

RHMDDMSSQSSRI PMSVDVGAIFGTRPAPRPTLNSADKSRLKRKLDMDPEFGYTE

424
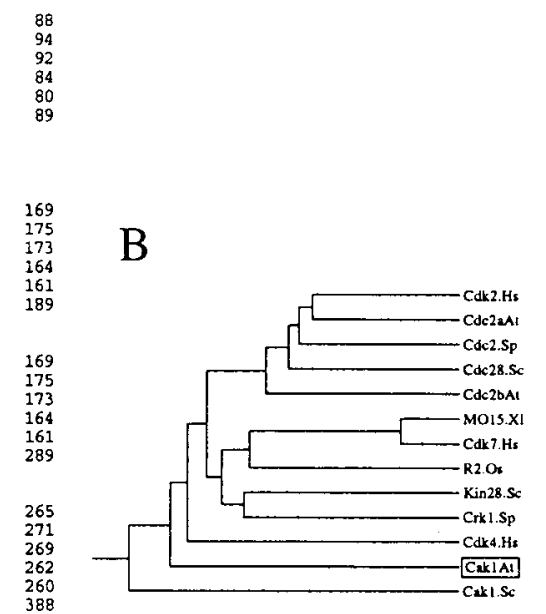

FIG. 1. Amino acid similarity of Cak1At to other CAK proteins. $(A)$ Predicted amino acid sequence of Cak1At and alignment with CAK proteins from other organisms. Identical amino acids are indicated by asterisks. Dashes represent gaps introduced to give maximal identity. The threonine residue indicated by + represents the phosphoregulatory site of CAK. (B) Phylogenetic tree obtained by amino acid sequence comparison of human Cdk2 (Cdk2.Hs), Cdk4 (Cdk4.Hs), Cdk7 (Cdk7.Hs), Xenopus MO15 (MO15.Xl), rice R2 (R2.Os), S. cerevisiae Cdc28 (Cdc28.Sc), Cak1 (Cak1.Sc), Kin28 (Kin28.Sc), Sch. pombe Cdc2 (Cdc2.Sp), Crk1 (Crk1.Sp), and Arabidopsis Cdc2aAt and Cdc2bAt.

Cak1At showed no significant sequence similarity to Cak1/ Civ1 of $S$. cerevisiae, although overexpression of cak1At on pYX112 rescued the temperature sensitivity of GF2351 cells at $37^{\circ} \mathrm{C}$ (Fig. $2 A$ ). When the Arabidopsis $c d c 2$ genes, $c d c 2 a A t$ and $c d c 2 b A t$, were overexpressed by using the same vector in GF2351, no colonies were formed at $37^{\circ} \mathrm{C}$, indicating that the $c d c 2$ genes were not capable of complementing the mutant.

Complementation of Fission Yeast CAK Mutant with cak1At. Because Cak1/Civ1 of $S$. cerevisiae is unique in comparison to CAKs of vertebrates and Sch. pombe (20-22), we tested whether cak1At can complement the fission yeast mutant JM1224, which carries an mcs6 mutation allelic to crk1/ mop1 causing a temperature-dependent cell cycle arrest (18, 35). Full-length coding region of caklAt was cloned into the pREP3 vector under the control of thiamin-repressible NMT1 promoter driving an inducible expression of cak1At. JM1224 cells expressing caklAt grew well at $35.5^{\circ} \mathrm{C}$, as shown in Fig. $2 B$, but upon repression of the caklAt expression with thiamin became sensitive to high temperature. When Arabidopsis $c d c 2 a A t$ and $c d c 2 b A t$ were expressed in JM1224 by using the pREP3 vector, the cells could not grow at $35.5^{\circ} \mathrm{C}$, indicating that cak1At, suppressing the temperature sensitivity of $m c s 6$ mutation, had a function distinct from Arabidopsis $c d c 2 \mathrm{~s}$. A control strain carrying the wild-type $m c s 6 / c r k 1 / m o p 1$ gene on pREP1 under the same NMT1 promoter was able to grow at $35.5^{\circ} \mathrm{C}$ in the presence and absence of thiamin (Fig. $2 B$ ), indicating a leakiness of NMT1 promoter and better complementation of the mcs6 mutation by the homologous Sch. pombe gene. Microscopic observation showed that JM1224 transformants carrying the $\mathrm{pREP} 3$ vector alone as control displayed an elongated shape at $35.5^{\circ} \mathrm{C}$ (Fig. $2 C$ ). When either cak1At or the fission yeast $c r k 1$ was expressed in JM1224 in the absence of thiamin, almost all cells became short (Fig. 2C). In contrast, cells showed an elongated shape when cultured under repressive conditions with thiamin at $35.5^{\circ} \mathrm{C}$ (data not shown). These results indicated that overexpression of cak1At or crk1 activated the cell division cycle, leading to a short-cell phenotype in fission yeast.
Molecular Characterization of cak1At. Arabidopsis genomic DNA was digested with diverse restriction enzymes and subjected to Southern DNA hybridization using an EcoRI fragment of $1.5 \mathrm{~kb}$, carrying the caklAt coding region, as probe (Fig. $3 A$ ). A single band of $2.3 \mathrm{~kb}$ was detected in the EcoRI digests, whereas Bam HI, which cleaved the $5^{\prime}$ end of the cDNA probe, also produced a single band. Three bands were detected with HindIII, which cleaved the cDNA at three sites, two of which were close together. SacI digestion also generated three bands, of which the 6-kb fragment showed relatively weak signal (Fig. 3A). Because two of the three SacI sites were located at the very $5^{\prime}$ and $3^{\prime}$ ends of the cDNA, respectively, the weak band corresponded to a genomic DNA fragment having homology with either the $5^{\prime}$ or the $3^{\prime}$ end of the cDNA probe. When the membrane was washed under low-stringency conditions, the hybridization pattern did not change (data not shown), indicating that the caklAt gene represented a single unique locus in the Arabidopsis genome.

To monitor cak1At expression, total Arabidopsis RNA was isolated from suspension culture, roots, cotyledons, seedlings, rosettes, stems, young siliques, and floral buds and was hybridized with the caklAt cDNA (Fig. 3B). Low levels of caklAt RNA of $1.8 \mathrm{~kb}$, corresponding well to the length of cDNA (1.7 $\mathrm{kb}$ ), were detected in almost all tissues. The cak1At mRNA level was found to be the highest in the suspension culture, suggesting a possible up-regulation in actively dividing cells.

Phosphorylation and Activation of Human CDK2 by Cak1At in Vitro. An antibody raised against a carboxylterminal peptide of Cak1At (PTSSGFTIEFP) detected a protein of $62 \mathrm{kDa}$ in a crude protein extract prepared from proliferating cells of an Arabidopsis suspension (Fig. 4A). The same protein was also observed in a protein sample extracted from budding yeast GF2351 transformants expressing cak1At, but was absent from cells carrying an empty pYX112 vector as control (Fig. 4A). These data showed that the antibody recognized properly the Arabidopsis Cak1At protein showing an apparent molecular mass of $62 \mathrm{kDa}$. The Cak1At protein could also be immunoprecipitated from Arabidopsis crude 
A
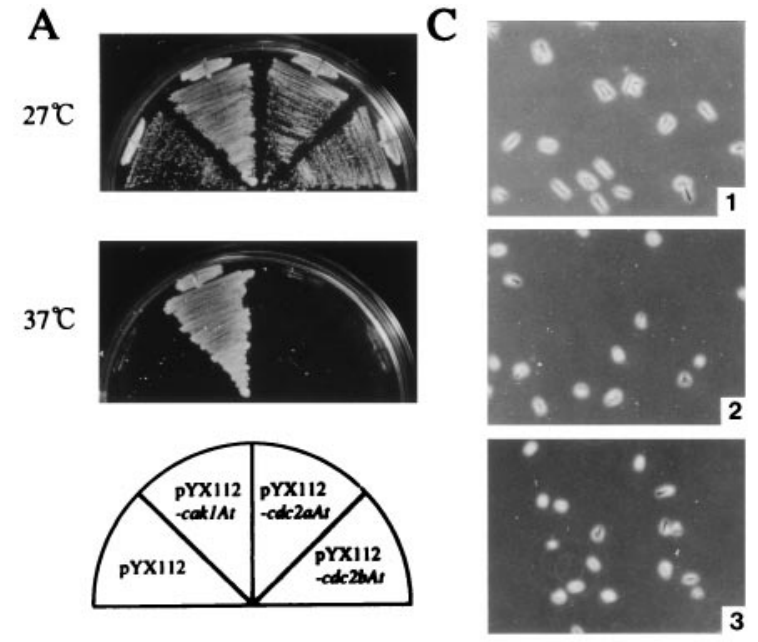

B

$27 \mathrm{C}$
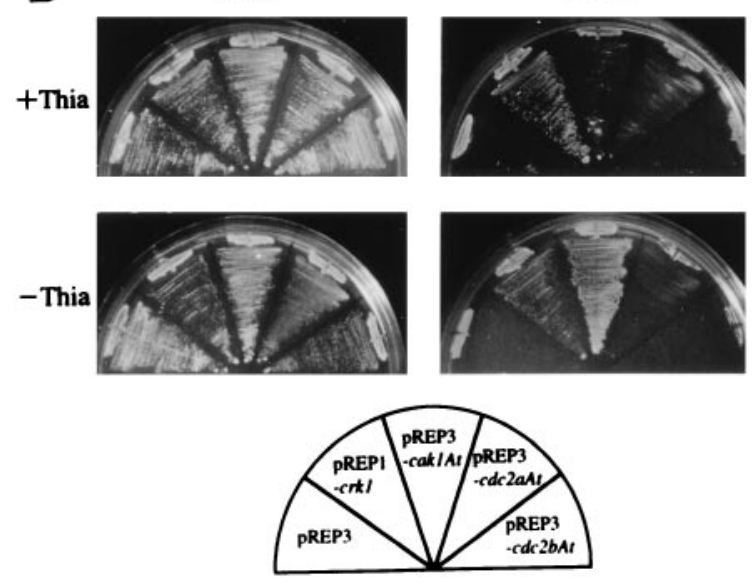

FIG. 2. Overexpression of cak1At suppresses the CAK mutations in budding and fission yeasts. (A) Complementation of the $S$. cerevisiae mutant GF2351. Transformants carrying each plasmid were incubated at $27^{\circ} \mathrm{C}$ or $37^{\circ} \mathrm{C}$ for 3 days. (B) Complementation of the Sch. pombe mutant JM1224. Transformants carrying each plasmid were grown in the absence (-Thia) or presence (+Thia) of thiamin at $27^{\circ} \mathrm{C}$ or $35.5^{\circ} \mathrm{C}$ for 6 days. (C) Morphology of JM1224 cells carrying the empty pREP3 vector (1), pREP1-crk1 (2), or pREP3-cak1At (3). Cells were grown in the absence of thiamin at $35.5^{\circ} \mathrm{C} .(\times 170$. $)$

extracts by using the antibody (Fig. $4 B$ ). The Cak1At immunoprecipitate was reacted with human CDK2 fused to GST, and phosphorylation of CDK2 was detected by autoradiography. To preclude the possibility of autophosphorylation, a kinase-inactive mutant of GST-CDK2, carrying a K33R replacement (11), was used as a substrate. The Cak1At immunoprecipitate phosphorylated the GST-CDK2 substrate, whereas those with the preimmune serum showed no activity (Fig. 4B). The GST control protein was not phosphorylated by either of these immunoprecipitates (data not shown). When GST-CDK2 in which T160 within the T-loop was replaced by an alanine (T160A) was used as substrate, no phosphorylation was observed (Fig. 4B), indicating that the immunoprecipitate specifically phosphorylated T160 of CDK2. In the next step, Cak1At immunoprecipitates were incubated with GST-CDK2 in the presence of human cyclin $\mathrm{A}$, and the reaction mixture was subjected to a histone H1-kinase assay. Immunoprecipitates with the Cak1At antibody, but not with the preimmune serum, displayed histone $\mathrm{H} 1$ phosphorylation activity with CDK2 (wild type). However, only a background level of phosphorylation was observed with CDK2(K33R) and CDK2(T160A) (Fig. 4B), indicating that Cak1At was capable

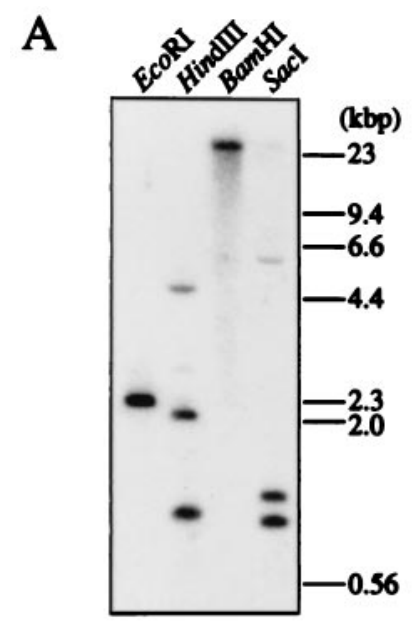

B

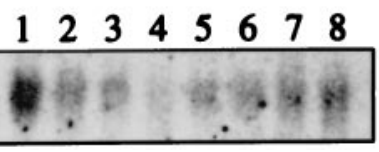

FIG. 3. Southern and Northern hybridizations of cak1At. (A) Southern blotting analysis of cak1At representing a single gene in the Arabidopsis genome. (B) Transcript levels of cak1At in different Arabidopsis tissues. Total RNA samples $(12 \mu \mathrm{g})$ were subjected to Northern blotting. Lanes are as follows: 1 , suspension culture; 2 , root; 3, cotyledon; 4, seedling; 5, rosette; 6, stem; 7, silique; and 8, floral bud.

of specifically activating the human CDK2-cyclin A complex to phosphorylate histone $\mathrm{H} 1$.

CTD Phosphorylation Depends on a CDK Other than Cak1At. Vertebrate CAKs phosphorylate not only CDKs but also the CTD of the largest subunit of RNA polymerase II. Therefore, we searched for CTD kinases in Arabidopsis and tested whether they correspond to Cak1At. Proteins extracted from Arabidopsis suspension culture were separated by DEAESepharose chromatography to fraction K1, representing the flow-through, and $\mathrm{K} 2$, containing proteins eluted with $0.6 \mathrm{M}$ $\mathrm{NaCl}$ (46). CTD kinase activity was observed exclusively in the $\mathrm{K} 1$ fraction, whereas Cak1At was immunologically detected only in the $\mathrm{K} 2$ fraction (Fig. $4 C$ ), suggesting that protein kinases other than Cak1At in the K1 fraction were responsible for the CTD phosphorylation activity.

The yeast protein $\mathrm{p} 13^{\text {suc1 }}$ forms a tight complex with Cdc2related protein kinases in plants $(40,47,48)$. On the basis of the fact that the CTD kinase Kin28 is a relative of Cdc28 in $S$. cerevisiae (29), Arabidopsis proteins interacting with p13 $13^{\text {suc1 }}$ were assayed for CDK2 and CTD kinase activities. In fact, CTD was phosphorylated by Arabidopsis proteins precipitated by $\mathrm{p} 13^{\text {suc1 }}$-agarose, but showed no CDK2 kinase activity (Fig. $4 D)$. Immunoblotting of these proteins showed that Cak1At did not bind to $\mathrm{p} 13^{\text {suc } 1}$-agarose (Fig. $4 D$ ), demonstrating again that in Arabidopsis a Cdc2-related protein kinase different from Cak1At phosphorylated the CTD but not the CDK2 kinase.

\section{DISCUSSION}

We have identified an Arabidopsis cDNA named cak1At that encodes a protein kinase similar to CDKs. Cak1At shows the closest similarity to the $\mathrm{p} 40^{\mathrm{MO} 15} / \mathrm{Cdk} 7$ kinase family within specific domains, including the ATP-binding and kinase activesites. Other CDK regions were less conserved in Cak1At which therefore cannot be classified to the group of $\mathrm{Cdc} 2 / \mathrm{Cdc} 28$ and $\mathrm{p} 40^{\mathrm{MO} 15} / \mathrm{Cdk} 7$ kinases in the phylogenetic tree. An insertion of 112 amino acids between the kinase active site and the 


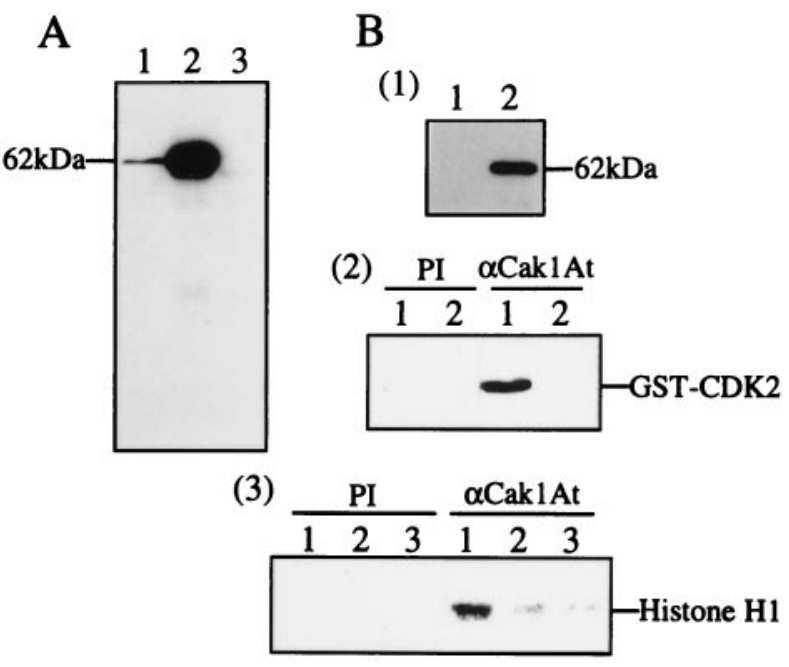

C

D

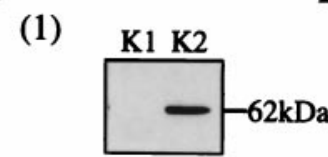

(1) $1 \begin{array}{lll}1 & 2 & 3\end{array}$
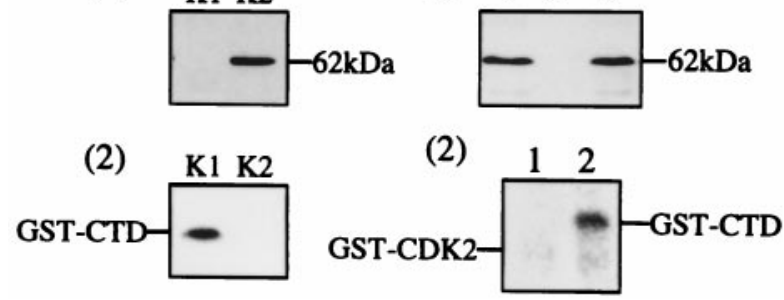

FIG. 4. Immunological detection of Cak1At and assay for CDK2 kinase, CTD kinase, and CAK activities. $(A)$ Twenty-five micrograms of Arabidopsis crude protein extract (lane 1) and $10 \mu \mathrm{g}$ of total protein extract from $S$. cerevisiae GF2351 cells carrying pYX112-cak1At (lane 2 ) or the empty pYX112 vector (lane 3 ) was immunoblotted with the anti-Cak1At antibody. (B) (1) Immunoprecipitates of Arabidopsis proteins with preimmune serum (lane 1) or the anti-Cak1At antibody (lane 2) were subjected to immunoblotting with the anti-Cak1At antibody. (2) Immunoprecipitates of Arabidopsis proteins with preimmune serum or the anti-Cak1At antibody were assayed for CDK2 kinase activity with GST-CDK2 (K33R) (lane 1) or GST-CDK2 (T160A) (lane 2). (3) Immunoprecipitates of Arabidopsis proteins obtained with preimmune serum or the anti-Cak1At antibody were assayed for CDK2-activating kinase (CAK) activity, using GST-CDK2 (wild type) (lane 1), GST-CDK2 (K33R) (lane 2), or GST-CDK2 (T160A) (lane 3) as substrates. (C) (1) Ten micrograms of K1 and K2 fractions of Arabidopsis proteins was immunoblotted with the antiCak1At antibody. (2) K1 and K2 fractions of Arabidopsis proteins were mixed with GST-CTD, and CTD-associated proteins were subjected to phosphorylation reaction. (D) (1) Arabidopsis total protein (lane 1), p13 $3^{\text {suc1 }}$-associated proteins (lane 2), and the supernatant after depletion of $\mathrm{p} 13^{\text {suc1 }}$-associated proteins (lane 3 ) were immunoblotted with the anti-Cak1At antibody. (2) p13 $3^{\text {suc1 }}$-associated proteins were assayed for CDK2 or CTD kinase activity.

phosphoregulatory site is a unique feature of Cak1At, although the functional significance of this kinase domain remains to be established.

cak1At has been isolated by complementation of the budding yeast mutant GF2351. When cak1At was overexpressed in the fission yeast mutant JM1224, it also rescued the temperature sensitivity of the $m c s 6-13$ mutation. Because overexpression of Arabidopsis cdc2aAt or $c d c 2 b A t$ could not suppress the CAK mutations in budding yeast GF2351 and fission yeast JM1224, the gene product of cak1At has a function distinct from that of $\mathrm{Cdc} 2$ proteins. Cak1At appeared to be similar to CAK MO15 of Xenopus, which was shown to suppress the mcs6-13 mutation in JM1224 (18). However, MO15 alone did not complement the budding yeast mutant GF2351 (C. Miled and C. Mann, personal communication). It is remarkable therefore that Cak1At is capable of rescuing the temperature sensitivity of both fission and budding yeast CAK mutants. Because CAKs of budding and fission yeasts are completely different from each other, it appears that Arabidopsis Cak1At may function in a unique way in activation of CDKs.

Immunoprecipitates with the Cak1At antibody were able to phosphorylate human CDK2(K33R) but not CDK2(T160A), indicating that Cak1At specifically phosphorylates T160 of CDK2. In the CAK assay, histone $\mathrm{H} 1$ was phosphorylated in the presence of human CDK2 (wild type) and cyclin A, showing that the CAK immunoprecipitates activated the CDK2 kinase. These data suggest that in fact Cak1At may function as a CDK-activating kinase in Arabidopsis.

We showed that Cak1At is chromatographically separable in the $\mathrm{K} 2$ fraction of DEAE-Sepharose from the bulk of CTD kinase activity recovered in the flow-through K1 fraction. As in alfalfa (46), the yeast protein $\mathrm{p} 13^{\text {suc1 }}$ specifically extracted the CTD kinase activity from the Arabidopsis crude extract. However, neither the Cak1At protein nor the CDK2 kinase activity was associated with the CTD kinase bound by $\mathrm{p} 13^{\text {suc1 }}$, indicating that the $\mathrm{p} 13^{\mathrm{suc} 1}$-interacting CDK-like proteins have no activity in phosphorylating CDK2. Moreover, the $S$. cerevisiae mutant JGV4 carrying the kin28-ts3 mutation (31) could not be rescued by overexpression of caklAt (data not shown), indicating that cak1At overexpression cannot suppress the defect of CTD kinase in JGV4 cells. Therefore, it is likely that in Arabidopsis different protein kinases function in the phosphorylation of CDKs and CTD of RNA polymerase II, as is the case in $S$. cerevisiae. This is in contrast to vertebrates or fission yeast, where CAKs are involved in phosphorylation of both CTD and CDKs $(8,27)$. Arabidopsis may thus carry another protein kinase similar to Kin28 that might be involved in the regulation of basal transcription by phosphorylating CTD. This assumption is also supported by the fact that the CTD kinase activity in Arabidopsis was found to be associated with $\mathrm{p} 13^{\text {suc1}}$, indicating that CTD-kinase is a member of the CDK family.

It is known that Cak1/Civ1 of budding yeast has no similarity to other CDKs (20-22). CAKs of vertebrates and fission yeast require an association with specific cyclin partners for their activity, whereas Cak1/Civ1 is active as a monomer. In the case of Arabidopsis Cak1At, no CAK activity was detected in vitro with the GST-Cak1At fusion protein (data not shown), suggesting that Cak1At may require either a post-translational modification or association with regulatory subunit(s) for its activity. This feature is completely different from that of Cak1/Civ1, which as GST-fusion protein shows CAK activity (21). The anti-Cak1At antibody detected a protein of $62 \mathrm{kDa}$, although the molecular mass of Cak1At deduced from the amino acid sequence is about $54 \mathrm{kDa}$. This discrepancy in molecular mass may indeed reflect a modification, such as activating phosphorylation in vivo, that changes the mobility of Cak1At on SDS/PAGE. Further analysis is necessary to reveal whether Cak1At is associated with other regulatory proteins.

In rice, the amino acid sequence of $\mathrm{CDK} / \mathrm{CAK}$ homologue R2 was found to be very similar to Kin 28 of budding yeast. In fact, R2 is included in the same cluster as p $40^{\mathrm{MO} 15} / \mathrm{Cdk} 7$ in the phylogenetic tree (Fig. $1 B$ ). However, immunoprecipitates with the R2 antibody had no CDK2 kinase or CAK activity, but they showed a high CTD kinase activity (unpublished data). Therefore, Arabidopsis Cak1At appears to be the first protein kinase in plants that has been characterized in terms of CAK activity. Gene caklAt represents a single chromosomal locus in the Arabidopsis genome, which is transcribed at a very low level in all tissues but is highly expressed in proliferating cells of suspension cultures. It is therefore likely that the activity of Cak1At is regulated not only at a post-translational level by, e.g., phosphorylation of the threonine residue at the phosphoregulatory site, but also transcriptionally. Screening for Cak1At-interacting proteins may further identify positive or 
negative effectors of Cak1At in CDK regulation. Isolation of mutants defective in cak1At, on the other hand, may facilitate a genetic dissection of cell cycle regulatory events related to CAK and CDKs controlling a flexible cell proliferation throughout the life cycle of higher plants.

We appreciate Dr. László Bakó's useful suggestions throughout this work. We thank Dr. Carl Mann for providing us the GF2351 cells. We are also grateful to Dr. Jonathan Millar for sending the JM1224 cells and pREP1-crk1 plasmids. We thank Dr. Katsumi Yamashita for the GST-CDK2 and His-cyclin A plasmids and helpful discussions. We thank Dr. Takashi Ueda for his help in Northern hybridization. This work was supported by a Grant-in-Aid for Scientific Research from the Ministry of Education, Science and Culture of Japan.

1. Solomon, M. J. (1993) Curr. Opin. Cell Biol. 5, 180-186.

2. King, R. W., Jackson, P. K. \& Kirschner, M. W. (1994) Cell 79, 563-571.

3. Lees, E. (1995) Curr. Opin. Cell Biol. 7, 773-780.

4. Morgan, D. O. (1995) Nature (London) 374, 131-134.

5. Pines, J. (1995) Biochem. J. 308, 697-711.

6. Jeffrey, P. D., Russo, A. A., Polyak, K., Gibbs, E., Hurwitz, J., Massagué, J. \& Pavletich, N. P. (1995) Nature (London) 376, 313-320.

7. Morgan, D. O. (1996) Curr. Opin. Cell Biol. 8, 767-772.

8. Fisher, R. P. (1997) Curr. Opin. Genet. Dev. 7, 32-38.

9. Doerner, P., Jørgensen, J.-E., You, R., Steppuhn, J. \& Lamb, C. (1996) Nature (London) 380, 520-523.

10. Fesquet, D., Labbé, J.-C., Derancourt, J., Capony, J.-P., Galas, S., Girard, F., Lorca, T., Shuttleworth, J., Dorée, M. \& Cavadore, J.-C. (1993) EMBO J. 12, 3111-3121.

11. Poon, R. Y. C., Yamashita, K., Adamczewski, J. P., Hunt, T. \& Shuttleworth, J. (1993) EMBO J. 12, 3123-3132.

12. Solomon, M. J., Harper, J. W. \& Shuttleworth, J. (1993) EMBO J. 12, 3133-3142.

13. Fisher, R. P. \& Morgan, D. O. (1994) Cell 78, 713-724.

14. Mäkelä, T. P., Tassan, J.-P., Nigg, E. A., Frutiger, S., Hughes, G. J. \& Weinberg, R. A. (1994) Nature (London) 371, 254-257.

15. Devault, A., Martinez, A.-M., Fesquet, D., Labbé, J.-C., Morin, N., Tassan, J.-P., Nigg, E. A., Cavadore, J.-C. \& Dorée, M. (1995) EMBO J. 14, 5027-5036.

16. Fisher, R. P., Jin, P., Chamberlin, H. M. \& Morgan, D. O. (1995) Cell 83, 47-57.

17. Tassan, J.-P., Jaquenoud, M., Fry, A. M., Frutiger, S., Hughes, G. J. \& Nigg, E. A. (1995) EMBO J. 14, 5608-5617.

18. Buck, V., Russell, P. \& Millar, J. B. A. (1995) EMBO J. 14, 6173-6183.

19. Damagnez, V., Mäkelä, T. P. \& Cottarel, G. (1995) EMBO J. 14, 6164-6172.

20. Espinoza, F. H., Farrell, A., Erdjument-Bromage, H., Tempst, P. \& Morgan, D. O. (1996) Science 273, 1714-1717.

21. Kaldis, P., Sutton, A. \& Solomon, M. J. (1996) Cell 86, 553-564.

22. Thuret, J.-Y., Valay, J.-G., Faye, G. \& Mann, C. (1996) Cell 86, $565-576$.
23. Roy, R., Adamczewski, J. P., Seroz, T., Vermeulen, W., Tassan, J.-P., Schaeffer, L., Nigg, E. A., Hoeijmakers, J. H. J. \& Egly, J. M. (1994) Cell 79, 1093-1101.

24. Serizawa, H., Mäkelä, T. P., Conaway, J. W., Conaway, R. C., Weinberg, R. A. \& Young, R. A. (1995) Nature (London) 374, 280-282.

25. Shiekhattar, R., Mermelstein, F., Fisher, R. P., Drapkin, R., Dynlacht, B., Wessling, H. C., Morgan, D. O. \& Reinberg, D. (1995) Nature (London) 374, 283-287.

26. Seroz, T., Hwang, J. R., Moncollin, V. \& Egly, J. M. (1995) Curr. Opin. Gen. Dev. 5, 217-221.

27. Nigg, E. A. (1996) Curr. Opin. Cell Biol. 8, 312-317.

28. Draetta, G. F. (1997) Curr. Biol. 7, R50-R52.

29. Simon, M., Seraphin, B. \& Faye, G. (1986) EMBO J. 5, $2697-$ 2701.

30. Valay, J. G., Simon, M. \& Faye, G. (1993) J. Mol. Biol. 234, 307-310.

31. Valay, J. G., Simon, M., Dubois, M. F., Bensaude, O., Facca, C. \& Faye, G. (1995) J. Mol. Biol. 249, 535-544.

32. Feaver, W. J., Svejstrup, J. Q., Henry, N. L. \& Kornberg, R. D. (1994) Cell 79, 1103-1109.

33. Cismowski, M. J., Laff, G. M., Solomon, M. J. \& Reed, S. I. (1995) Mol. Cell. Biol. 15, 2983-2992.

34. Glab, N., Labidi, B., Qin, L.-X., Trehin, C., Bergounioux, C. \& Meijer, L. (1994) FEBS Lett. 353, 207-211.

35. Molz, L., Booher, R., Young, P. \& Beach, D. (1989) Genetics 122, 773-782.

36. Umeda, M. \& Uchimiya, H. (1994) Plant Physiol. 106, 1015-1022.

37. Gietz, D., St. Jean, A., Woods, R. A. \& Schiestl, R. H. (1992) Nucleic Acids Res. 20, 1425.

38. Higgins, D. G., Bleasby, A. J. \& Fuchs, R. (1992) Comput. Appl. Biosci. 2, 189-191.

39. Prentice, H. L. (1992) Nucleic Acids Res. 20, 621.

40. Magyar, Z., Mészáros, T., Miskolczi, P., Deak, M., Fehér, A., Brown, S., Kondorosi, E., Athanasiadis, A., Pongor, S., Bilgin, M., Bakó, L., Koncz, C. \& Dudits, D. (1997) Plant Cell 9, 223-235.

41. Dunn, B. \& Wobbe, C. R. (1990) in Current Protocols in Molecular Biology, eds. Ausubel, F. M., Brent, R., Kingston, R. E., Moore, D. D., Seidman, J. G., Smith, J. A. \& Struhl, K. (WileyInterscience, New York), pp. 13.13.1-13.13.9.

42. Nawrath, C., Schell, J. \& Koncz, C. (1990) Mol. Gen. Genet. 223, 65-75.

43. Shure, M., Wessler, S. \& Fedoroff, N. (1983) Cell 35, 225-233.

44. Sambrook, J., Fritsch, E. F. \& Maniatis, T. (1989) in Molecular Cloning: A Laboratory Manual (Cold Spring Harbor Lab. Press, Plainview, NY), 2nd Ed., pp. 7.39-7.52.

45. Ueda, T., Matsuda, N., Anai, T., Tsukaya, H., Uchimiya, H. \& Nakano, A. (1996) Plant Cell 8, 2079-2091.

46. Bakó, L., Nuotio, S., Dudits, D., Schell, J. \& Koncz, C. (1994) in Plant Promoters and Transcription Factors, Results and Problems in Cell Differentiation, ed. Nover, L. (Springer, Berlin), Vol. 20, pp. 25-64.

47. Magyar, Z., Bakó, L., Bögre, L., Dedeoglu, D., Kapros, T. \& Dudits, D. (1993) Plant J. 4, 151-161.

48. Grafi, G. \& Larkins, B. A. (1995) Science 269, 1262-1264. 